\title{
Prolog: Eine Gebrauchs- und Leseanweisung
}

Diese Einführung geht davon aus, dass die/der Leser^in nicht vertraut ist mit den gängigen, oftmals technischen Termini der hier einzuführenden Disziplinen. Daher werden sämtliche Begriffe definiert, auch in Wiederholung an späterer Stelle im Text. Die Einzelkapitel funktionieren prinzipiell autonom, allerdings kann es manchmal hilfreich sein, die Einleitung als Basiswissen heranzuziehen. Die Einleitung stellt die facettenreiche Thematik zusammenfassend dar, ist damit in a nutshell das, was auf Sie zukommen wird.

Diese Einführung baut auf die Neugier und Geduld der Leser`in, denn viele Zitate der Originalquellen, häufig in englischer Sprache, werden herangezogen. Die Zitate werden in ihren jeweiligen Kontexten zitiert, damit ergeben sich häufig längere Passagen, die allerdings der Leser`in helfen sollen, die jeweiligen Argumente selbst einordnen und bewerten zu können. In den meisten Fällen werden die Zitate bzw. die wesentlichen Punkte vom Autor kurz zusammengefasst. Die Fußnoten sind dabei notwendige Ergänzungen, die in vielen Fällen nicht zu überlesen sind. Eine Reihe von Abbildungen, Grafiken und Diagrammen ergänzen an ausgewählten Stellen den Text. Die Internetquellen werden an den jeweiligen Stellen zitiert und nicht gesondert in der Bibliografie aufgenommen.

Als Weiteres ist anzumerken, dass neben den fachlichen Zitaten zu Begriffen, Modellen und Theorien, vor allem populäre Textbeispiele herangezogen werden, also Beispiele aus Romanen, Filmen und Zeitungen. Diese Beispiele sollen der Leser`in die alltägliche Relevanz der hier präsentierten Konzepte belegen. Auch ist dies ein Versuch, über Beispiele aus dem Alltagsleben die teilweise recht abstrakten Ansätze greifbar zu machen. An manchen Stellen ist es durchaus sinnvoll, die Beispiele ein zweites Mal zu lesen, deshalb auch die erhoffte Geduld beim Lesen.

Die Fachliteratur ist auf dem neuesten Stand ausgehend vom Buchdruck im Sommer 2018. Die Grundlagentexte werden an den gegebenen Stellen aufgelistet. Eine ausführliche Bibliografie findet sich am Ende der Einführung.

Bleibt nur noch zu schreiben, dass der Autor der Leser`in für das Interesse und die Geduld im Voraus danken möchte. 
